\title{
Tuberculous Meningitis and COVID-19 Co-Infection: About a Case
}

\author{
Ayoub Maaroufi ${ }^{\circledR}$, Abdellatif Diai, Nouredine Jebbar, Lotfi Bibiche, Kaissi Jaber, Nabil Jbili, \\ Hicham Kechna, Jaouad Laoutid
}

CHU Hassan II, Fes, Morocco

Email: maaroufiayoubmed@gmail.com

How to cite this paper: Maaroufi, A., Diai, A., Jebbar, N., Bibiche, L., Jaber, K., Jbili, N., Kechna, H. and Laoutid, J. (2021) Tuberculous Meningitis and COVID-19 CoInfection: About a Case. Open Journal of Clinical Diagnostics, 11, 52-58.

https://doi.org/10.4236/ojcd.2021.112004

Received: February 28, 2021

Accepted: June 26, 2021

Published: June 29, 2021

Copyright $\odot 2021$ by author(s) and Scientific Research Publishing Inc. This work is licensed under the Creative Commons Attribution International License (CC BY 4.0).

http://creativecommons.org/licenses/by/4.0/

\begin{abstract}
We report the case of an adult patient diagnosed with acute SARS-CoV-2associated meningoencephalitis based on the detection of its RNA on a nasopharyngeal swab, cerebrospinal fluid analysis. The most destructive type of extrapulmonary tuberculosis is tuberculous meningitis, in which the consequences are severe, resulting in death or disability in almost half of all sufferers despite anti-tuberculosis chemotherapy. The aim of this study was to assess the clinical and paraclinical features and laboratory findings and outcome of a patient with tuberculous meningitis and COVID-19 coinfection. Infection of COVID-19 and lymphopenia promotes the development of the severe form of tuberculosis. On the other hand, TBM increased the risk of infection with coronavirus due to the weakened immune system in addition to other immunosuppressive factors (older age and comorbidities such as low socioeconomic status and malnutrition). The patient had a good recovery even if he required intensive neurorehabilitation for a month due to poor feeding and weakness. Treatment, both anti-mycobacterial and anti-inflammatory, early started, guaranteed good recovery.
\end{abstract}

\section{Keywords}

Tuberculous Meningitis, Meningoencephalitis, COVID-19, Critical Care

\section{Introduction}

The severe acute respiratory syndrome coronavirus 2 (SARS-CoV-2) disease (COVID-19) pandemic is current public health and humanitarian issue because of its global rapid spread, clinical severity, high mortality rate, and capacity to overwhelm healthcare systems [1] [2].

There is a paucity of literature describing extra-pulmonary co-infection with 
Mycobacterium tuberculosis in COVID-19 patients, which is a major cause of ill health. In 2019, about 10 million people developed TB and 1.4 million died [3].

Mycobacterium tuberculosis can cause disease, or tuberculosis, in almost any organ. However, when it infects the brain and causes tuberculous meningitis (TBM) the consequences are severe, resulting in death or disability in almost half of all sufferers despite anti-tuberculosis chemotherapy [4].

Currently, Morocco is one of the worst affected COVID-19 pandemic countries with almost 480,000 cases [5] and also one the highest tuberculosis (TB) burden countries with an incidence of $87 / 100,000$ population in 2019 [6].

We report a case of tuberculous meningitis (TBM) and COVID-19 co-infection in a diabetic patient.

\section{Case Report}

A 65-year-old man with no significant medical history (non-insulin-dependent diabetes), and especially no history of pulmonary TB, presented to the hospital owing to low consciousness and fever.

There was no history of either known exposures to tuberculosis or COVID-19. Physical examination showed the signs of dehydration, malnutrition; respiratory frequency was 18 cycles/min, saturation measured $97 \%$.

Neurological examination revealed a depressed level of consciousness, with a Glasgow Coma Scale of 12 (E-4, V-4 and M-4), There was no neck stiffness, no Kernig and Brudzinski's sign, and no cranial nerve palsy. Examination of the other systems proved unremarkable. CT brain scan was normal (Figure 1).

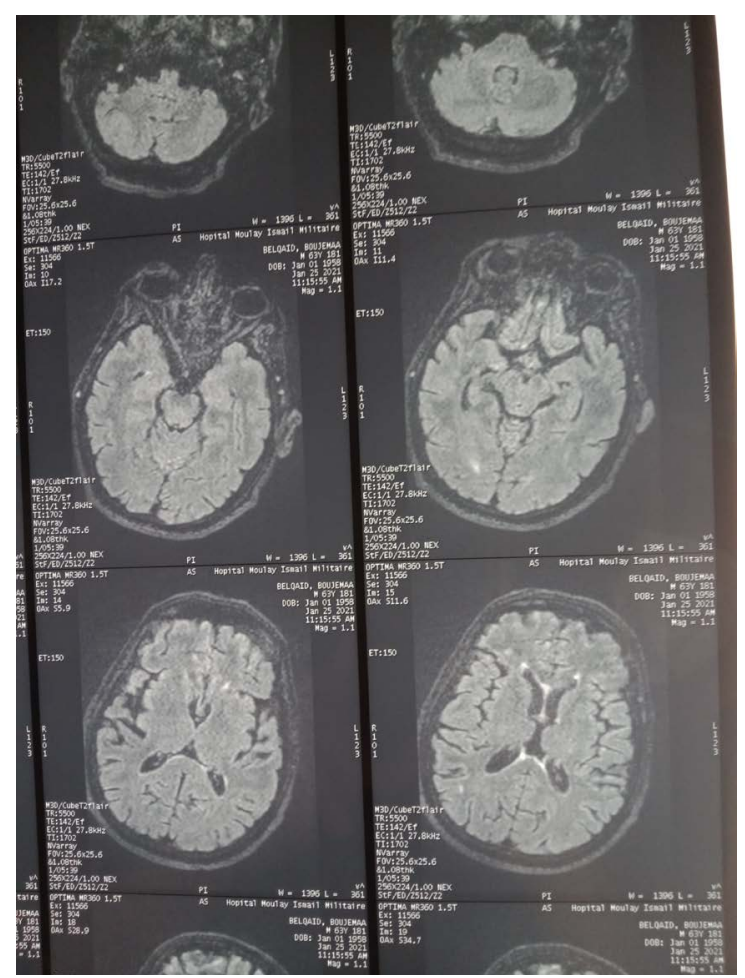

Figure 1. Normalbrain RMI. 
Cerebrospinal fluid (CSF) studies showed clear and colourless fluid with a white blood cell count of $280 / \mathrm{mm}^{3}$ ( $90 \%$ lymphocytes), red blood cell count of $64 / \mathrm{mm}^{3}$, hyperproteinorachia $(1.49 \mathrm{~g} / \mathrm{dL})$, and hypoglycorrhachia $(0.67 \mathrm{~g} / \mathrm{dL})$. Empiric antibiotic therapy was started.

Polymerase chain reaction on a nasal swab confirmed COVID-19 diagnosis.

Patient had chest Computerized Tomography (CT) highly suggestive of COVID19 related pneumonia (bilateral ground glass opacities at 15\%) [5], Left basal lung disease, bilateral apical tuberculosis sequelae, right apical excavated nodule, sequelae of right renal and vesical tuberculosis and moderate pyelocaliceal dilation of the left kidney (Figures 2-4).

A second lumbar puncture was performed; CSF was GeneXpert MTB/RIF positive and rifampicin resistance undetected. SARS-CoV-2 RNA was not detected in CSF and bacterial culture was sterile.

Laboratory investigations showed a normal white cell count of $6.3 \times 10^{9} / \mathrm{L}$ (neutrophils 75\%, lymphocyte $15.5 \%$ ), haemoglobin of $13.6 \mathrm{~g} / \mathrm{dL}$, platelets of $330 \times 10^{9} / \mathrm{L}$ and lymphopenia $\left(0.99 \times 10^{9} / \mathrm{L}\right)$. The $\mathrm{C}$ reactive protein was normal $(6 \mathrm{mg} / \mathrm{L})$. Coagulation studies revealed elevated D-Dimer $(18 \mathrm{mg} / \mathrm{L})$ as well as elevated ferritin $(811 \mu \mathrm{g} / \mathrm{L})$. glycemia was $1.69 \mathrm{~g} / \mathrm{L}$. The kidney function, serum electrolytes and liver function test all proved normal.

The patient was commenced on antituberculous treatment: isoniazid $20 \mathrm{mg} / \mathrm{kg}$, rifampicin $20 \mathrm{mg} / \mathrm{kg}$, pyrazinamide $40 \mathrm{mg} / \mathrm{kg}$ and ethionamide $20 \mathrm{mg} / \mathrm{kg}$, as well as an anti-HIV protease inhibitor (lopinavir/ritonavir), azithromycin, multivitamins, zinc, intravenous dexamethasone and prophylactic anticoagulation.

The patient required intensive neurorehabilitation for a month due to poor feeding and weakness.

Currently, our patient is recovering well in neurology department.

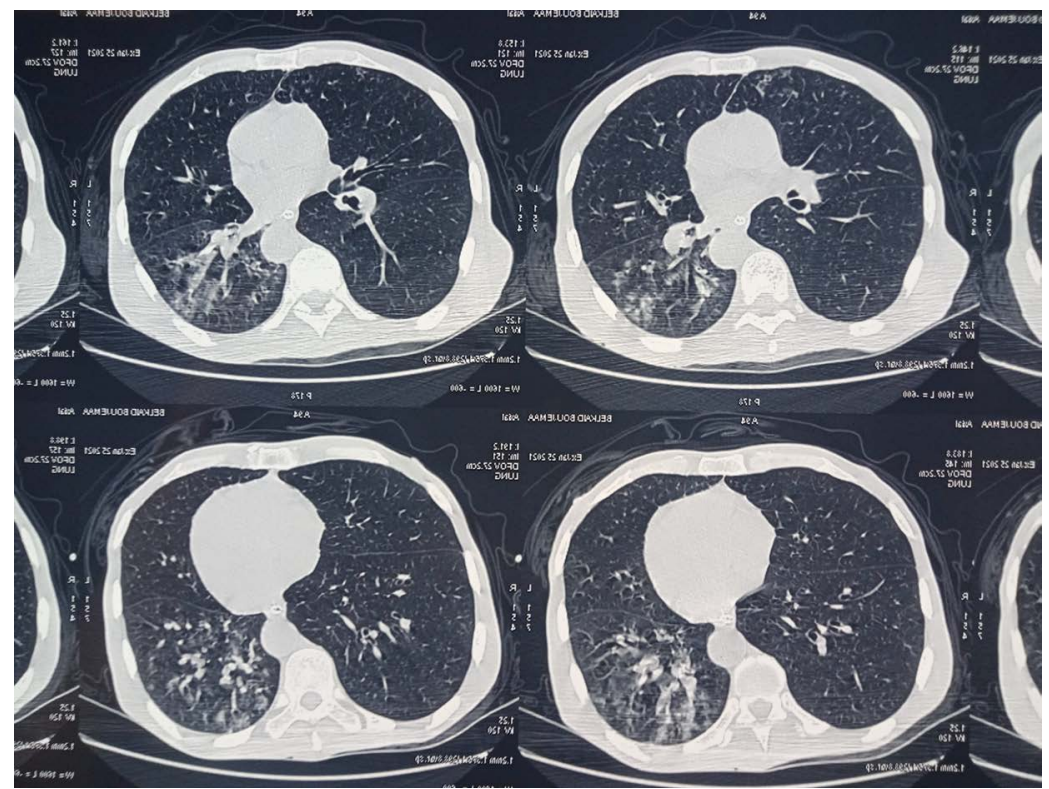

Figure 2. Chest scanner (2). 


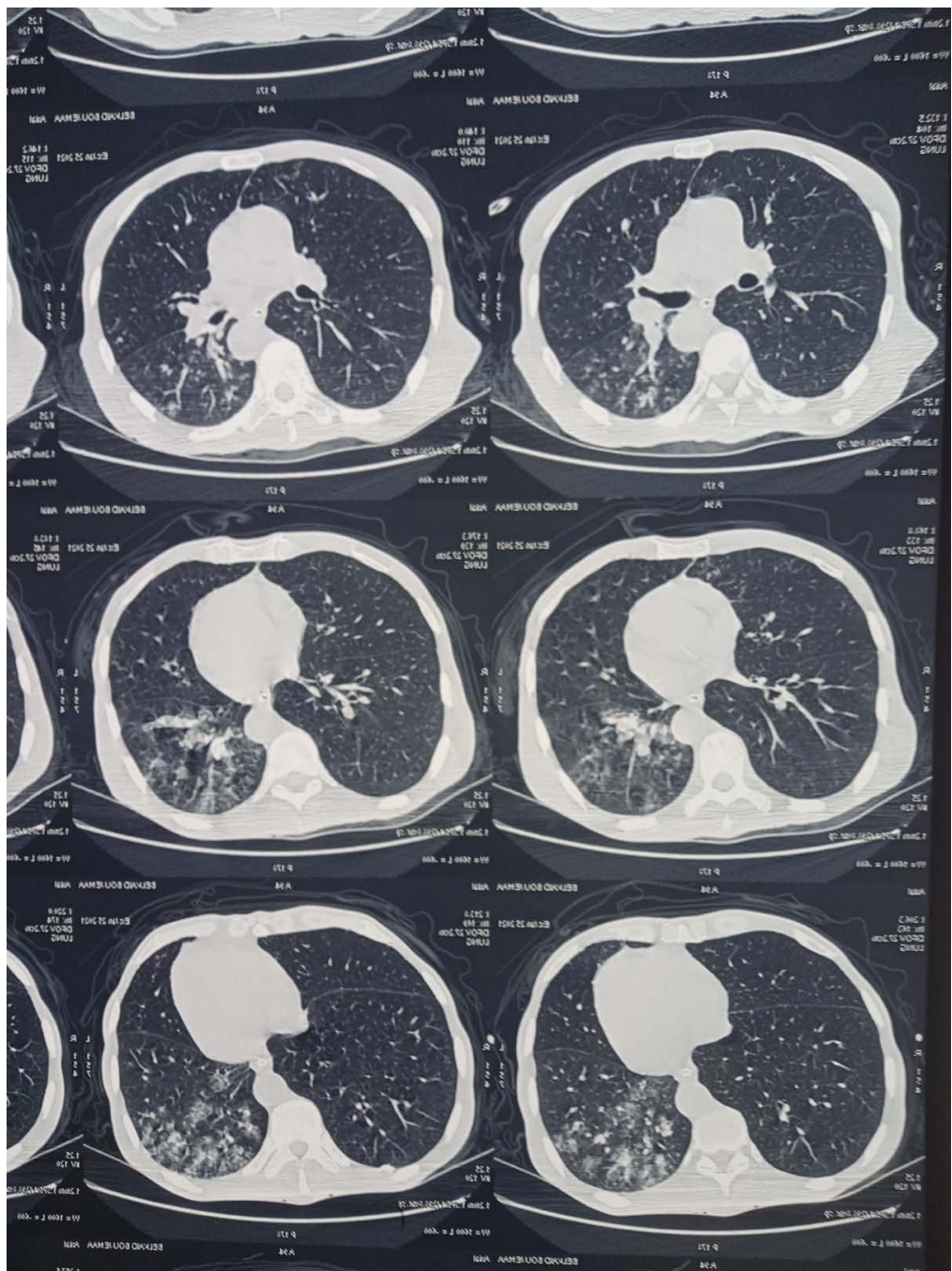

Figure 3. Chest scanner.

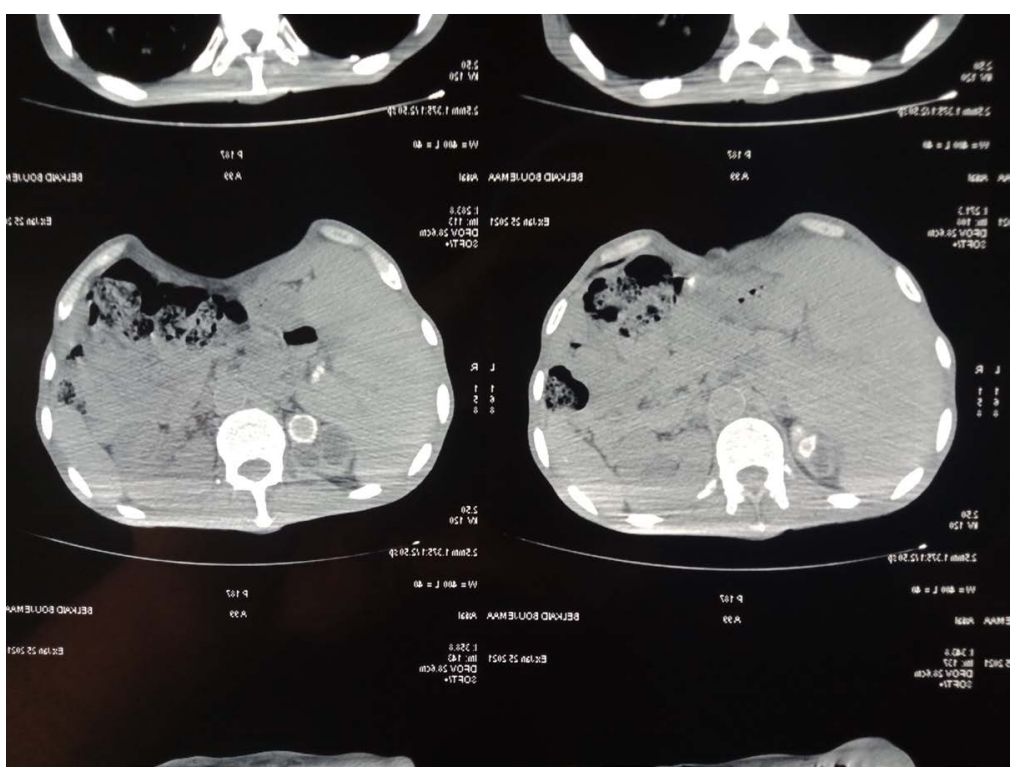

Figure 4. Abdominal scanner. 


\section{Discussion}

In December 2019, Coronavirus 2 (SRAS-CoV-2) pandemic caused severe acute respiratory syndrome. It broke out in Wuhan, China, generating a health crisis without precedent in recent history.

Coronavirus disease (COVID-19) manifests as a lung infection. However, patients with COVID-19 are also susceptible to suffer from other problems. In this study, our patient had both diseases diagnosed within the same week. The source of her tuberculous infection has not been identified and he had co-morbidities (non-insulin-dependent diabetes).

TBM accounts for $5 \%$ to $15 \%$ of extrapulmonary localizations and is the most severe infection with Mycobacterium tuberculosis [7]. Although there are no characteristic neurologic manifestations of TBM, some clinical findings in making the diagnosis include headache, fever, vomiting, altered conscious level and sometimes convulsions [4]. Clinical manifestations of TBM do not seem to be modified by COVID-19 infection.

Diagnosing TBM, even with advanced imaging techniques and anti-tuberculosis drugs is time-consuming and difficult because of its rarity; which is why the morbidity and mortality of TBM are still high [8]. The GeneXpert MTB/RIF) is a commercial, cartridge-based nucleic acid amplification test which detects DNA sequences specific for $\mathrm{M}$. tuberculosis and rifampicin resistance in clinical specimens in around $2 \mathrm{~h}$. We used it in our patient to confirm the diagnosis of the disease. However, it lacks the sensitivity and negative predictive value to confidently rule out TBM [9] [10]

The patient had persistent lymphopenia, which is a risk factor for severe tuberculosis [11].

Wenya Lin et al. concluded that patients with TBM, CRP level and CD4+ cell counts and albumin levels were lower than uninfected people [12]. Based on the results of this study, we concluded that TBM might suppress the immune system. In our case, TBM increased the risk of infection due to the weakened immune system. In addition, older age and co-morbidities such as low socioeconomic status and malnutrition increase the risk of weakening the immune system, making our patient more likely to be infected with corona virus.

Multiple studies have shown that viruses such as influenza, HIV, and measles can impair the ability of macrophages to contain mycobacterial growth, including Mycobacterium tuberculosis [13] [14]. We can deduce that infection of COVID-19 promotes the development of the severe form of TB which is TBM and then high mortality and morbidity.

In Morocco, treatment regimens for TBM are standardized and comply with international recommendations, in particular those of the WHO and the international union against tuberculosis and Lung diseases (IUATLD). The patient had received standard anti-tuberculosis treatment combining the four major anti-tuberculosis drugs which are rifampicin, isoniazid, pyrazinamide and ethambutol for two months then isoniazid and rifampicin are planned for seven months 
[15]. All the French and American learned societies recommend the use of corticosteroid therapy in addition to anti-tuberculosis treatment [16] [17], even if the results of the literature are not all consistent.

Like the pre-COVID-19 era, the diagnosis of TBM has been considered and specific anti-tuberculous therapy empirically initiated [18] but larger numbers are necessary to further understand the implication of TB and COVID-19 co-infection, given the potential effect of both TB and COVID-19 on quality of life and subsequent need for rehabilitation [19] [20].

\section{Conclusions}

In this case, we describe the clinical manifestations and outcome of tuberculous meningitis in a patient with COVID-19.

Infection of COVID-19 promotes the development of a severe form of TB. The patient had persistent lymphopenia, which is a risk factor for severe tuberculosis.

TBM is the most severe form of TB and it results in significant loss of autonomy and mortality.

On the other hand, TBM increased the risk of infection with coronavirus due to the weakened immune system in addition to other immunosuppressive factors.

Treatment, both anti-mycobacterial and anti-inflammatory, early started, guaranteed good recovery.

\section{Conflicts of Interest}

The authors declare no conflicts of interest regarding the publication of this paper.

\section{References}

[1] Worldometers (2020) COVID-19 Coronavirus Pandemic. https://www.worldometers.info/coronavirus

[2] Vitacca, M., Nava, S., Santus, P., et al. (2020) Early Consensus Management for Non-ICU ARF SARS-CoV-2 Emergency in Italy: From Ward to Trenches. European Respiratory Journal. https://doi.org/10.1183/13993003.00632-2020

[3] Sustainable Development Goals [Website]. United Nations, New York. https://sustainabledevelopment.un.org/topics/sustainabledevelopmentgoals

[4] Thwaites, G.E., van Toorn, R. and Schoeman, J. (2013) Tuberculous Meningitis: More Questions, Still Too Few Answers. The Lancet Neurology, 12, 999-1010. https://doi.org/10.1016/S1474-4422(13)70168-6

[5] https://github.com/CSSEGISandData/COVID-19

[6] Près de 30.000 cas de tuberculose sont enregistrés chaque année au Maroc, y compris les nouveaux cas et les cas de rechute.

https://www.medias24.com/30-000-cas-de-tuberculose-chaque-annee-au-maroc-11 $\underline{01 . h t m l}$

[7] Katti, M.K. (2004) Pathogenesis, Diagnosis, Treatment, and Outcome Aspects of 
Cerebral Tuberculosis. Medical Science Monitor, 10, RA215-RA229.

[8] Kent, S.J., Crowe, S.M., Yung, A., Lucas, C.R. and Mijch, A.M. (1993) Tuberculous Meningitis: A 30-Year Review. Clinical Infectious Diseases, 17, 987-994. https://doi.org/10.1093/clinids/17.6.987

[9] Boyles, T.H. and Thwaites, G.E. (2015) Appropriate Use of the Xpert(R) MTB/RIF Assay in Suspected Tuberculous Meningitis. International Journal of Tuberculosis and Lung Disease, 19, 276-277. https://doi.org/10.5588/ijtld.14.0805

[10] Bahr, N.C., Marais, S., Caws, M., et al. (2016) Tuberculous Meningitis International Research C: GeneXpert MTB/Rif to Diagnose Tuberculous Meningitis: Perhaps the First Test But Not the Last. Clinical Infectious Diseases, 62, 1133-1135. https://doi.org/10.1093/cid/ciw083

[11] Panteleev, A.V., Nikitina, I.Y., Burmistrova, I.A., Kosmiadi, G.A., Radaeva, T.V., Amansahedov, R.B., et al. (2017) Severe Tuberculosis in Humans Correlates Best with Neutrophil Abundance and Lymphocyte Deficiency and Does Not Correlate with Antigen-Specific CD4 T-Cell Response. Frontiers in Immunology, 8, 963. https://doi.org/10.3389/fimmu.2017.00963

[12] Lin, W. and Chen, P. (2020) Tubercular Meningitis in Patients with Systemic Lupus Erythematosus: Clinical Characteristics, Risk Factors, and Outcomes of 10 Patients. Clinical Rheumatology, 39, 1141-1145. https://doi.org/10.1007/s10067-020-04940-9

[13] Pathak, S., Wentzel-Larsen, T. and Åsjö, B. (2010) Effects of in Vitro HIV-1 Infection on Mycobacterial Growth in Peripheral Blood Monocyte-Derived Macrophages. Infection and Immunity, 78, 4022-4032. https://doi.org/10.1128/IAI.00106-10

[14] Whittaker, E., López-Varela, E., Broderick, C. and Seddon, J.A. (2019) Examining the Complex Relationship between Tuberculosis and Other Infectious Diseases in Children. Frontiers in Pediatrics, 7, 233. https://doi.org/10.3389/fped.2019.00233

[15] Melzer, M., Brown, T., Flood, J., Lacey, S. and Bagg, L. (1999) False Negative Polymerase Chain Reaction on Cerebrospinal Fluid Samples in Tuberculous Meningitis Established by Culture. Journal of Neurology, Neurosurgery and Psychiatry, 67, 249-250. https://doi.org/10.1136/jnnp.67.2.249a

[16] (2014) Recommandation de la Société de pneumologie de langue française sur la prise en charge de la tuberculose en France.

http://www.sp2a.fr/pdf/document/recommandations-prise-en-charge-tuberculose-f rance,108-.html

[17] American Thoracic Society, Center for Disease Control and Prevention, Infectious Disease Society of America (2003) Treatment of Tuberculosis. American Journal of Respiratory and Critical Care Medicine, 167, 603-662.

https://doi.org/10.1164/rccm.167.4.603

[18] Marais, S., Thwaites, G., Schoeman, J.F., Török, M.E., Misra, U.K., Prasad, K., et al. (2010) Tuberculous Meningitis: A Uniform Case Definition for Use in Clinical Research. The Lancet Infectious Diseases, 10, 803-812.

https://doi.org/10.1016/S1473-3099(10)70138-9

[19] Visca, D., Zampogna, E., Sotgiu, G., Centis, R., Saderi, L., D’Ambrosio, L., Pegoraro, V., Pignatti, P., Muňoz-Torrico, M., Migliori, G.B. and Spanevello, A. (2019) Pulmonary Rehabilitation Is Effective in Patients with Tuberculosis Pulmonary Sequelae. European Respiratory Journal, 53, Article ID: 1802184.

https://doi.org/10.1183/13993003.02184-2018

[20] Visca, D., Tiberi, S., Pontali, E., Spanevello, A. and Migliori, G.B. (2020) Tuberculosis in the Time of COVID-19: Quality of Life and Digital Innovation. European Respiratory Journal, 56, Article ID: 2001998.

https://doi.org/10.1183/13993003.01998-2020 